\title{
TRENDS IN SCREEN TIME BEHAVIOURS IN CZECH SCHOOLCHILDREN BETWEEN 2002 AND 2014: HBSC STUDY
}

\author{
Dagmar Sigmundová1, Erik Sigmund', Jens Bucksch², Petr Bad'ura', Michal Kalman¹, Zdeněk Hamřík \\ ${ }^{1}$ Faculty of Physical Culture, Palacký University Olomouc, Olomouc, Czech Republic \\ ${ }^{2}$ Department of Natural and Human Sciences, Prevention and Health Promotion, Heidelberg University of Education, Heidelberg, Germany
}

\section{SUMMARY}

Objective: Screen-based behaviours such as watching television or computer use are among the most prevalent sedentary behaviours adolescents spend time on. There is a lack of recent estimates on prevalence and changes in the amount of time spent on screen-based behaviour across Central and Eastern Europe. The main aim is to assess the trends in the prevalence of current recommendations for the screen time ( $\leq 2$ hours per day) of school-aged children in the Czech Republic between 2002 and 2014.

Methods: We used an internationally established methodology based on the Health Behaviour in School-aged Children (HSBC) study. Data was derived from Czech national representative samples of 11-, 13- and 15-year-olds collected in the years $2002(N=4,065), 2006(N=4,170)$, $2010(\mathrm{~N}=3,962)$ and $2014(\mathrm{~N}=4,338)$.

Results: The results indicated that the boys and girl surveyed in 2014 are up to two times more likely to meet the current recommendations for watching television in comparison with groups of schoolchildren of the same age surveyed in 2002. In contrast, computer use by adolescents increased markedly between 2006 and 2014. Taking total screen time into account, spending two hours per day or less on it decreased significantly among boys $(\mathrm{OR}=0.74,95 \% \mathrm{Cl}=0.62-0.89)$ and girls $(\mathrm{OR}=0.80,95 \% \mathrm{Cl}=0.70-0.92)$ between 2006 and 2014 .

Conclusions: As screen time is an important indicator of time spent in a sedentary way, our findings call for more interventions to reduce the time that school-aged children spend in front of screens.

Key words: sedentary behaviour, screen time, trend, adolescent, computer, television

Address for correspondence: D. Sigmundová, Faculty of Physical Culture, Palacký University Olomouc, trída Míru 117, 77111 Olomouc, Czech Republic. E-mail: dagmar.sigmundova@upol.cz

https://doi.org/10.21101/cejph.a4822

\section{INTRODUCTION}

Within the last decade, screen time behaviours such as excessive computer, tablet and smartphone use in adolescents, who have dealt with rapid technological developments, have contributed to the large amount of time that adolescents spend in an inactive way, preferring sedentary behaviour (1-4). Current studies point out that sedentary activities are relatively independent of physical activity, i.e. these two behaviours do not directly displace one another in youngsters and adults $(5,6)$. In addition, sedentary behaviours tend to start in childhood and adolescence and proceed into adulthood (7). A recent study found that adolescent boys with a high level of sedentary time also had three to five times higher odds of continuing to have high levels of sedentary time into young adulthood (8). Thus, it seems important to understand screen time behaviour as an important part of adolescents' life. Furthermore, different studies highlight that a greater amount of sedentary time is associated with negative health outcomes, including adverse effects on metabolic health (9), increased incidence of headaches, feeling low, being irritable, feeling nervous, stomach-ache, backache, and other health complaints (10-13). These associations are relatively independent of moderate to vig- orous physical activity. In addition, excessive television watching, computer gaming or other e-media use is also associated with risk behaviour such as bullying (14) or alcohol and cannabis use (15, 16). However, a few studies also report on positive associations of screen time behaviours in terms of enhanced self-esteem, the formation of relationships and the quality of friendships $(17,18)$. From a public health perspective, reducing screen time behaviours should be addressed in interventions, in addition to the promotion of physical activity.

The recommendation of a maximum of two hours per day or less of recreational television watching or use of other e-media (19-22) appears to be a reliable indicator for a risk of a poor diet and low levels of physical activity, and abiding by the recommendation should bring health benefits, such as a lower prevalence of overweight and obesity.

Although the evidence on the health benefits of reducing screen time behaviours is growing, across Central and Eastern Europe there is a lack of recent estimates on prevalence and changes in the amount of time adolescents spend engaged with screen-based behaviour or sedentary behaviours. In addition, these results are limited and vary between countries (23-27). Some studies reported a consistent amount of the total time spent sitting in front 
of a television or a computer, and they reveal that the time spent watching television was replaced by time spent using a computer $(28,29)$. Other studies found an increase in the time spent sitting in front of a television or computer (30-32). Further analyses that use the same methodology in different countries are needed to facilitate sound comparisons between countries. One of the tools applied in cross-national studies is the Health Behaviour in School-aged Children (HSBC) questionnaire, which also evaluates the time spent sitting in front of a television or a computer. Although the items in the HBSC questionnaire that relate to sedentary behaviour show moderate to borderline reliability (33, 34 ), the results are satisfactory because in the retest phase of the study approximately $60-80 \%$ of the respondents answered in the same category as in the test or an adjoining category. Moreover, the reliability of using a shortened test-and-retest period was greater (34).

This study used national HBSC data from the Czech Republic between 2002 and 2014 to assess the trends in recommended screen time by gender and age category. We analysed changes in the proportion of adolescents watching television and using a computer for at most two hours a day over the given period.

\section{MATERIALS AND METHODS}

Our data refers to the HSBC study and was approved by the Ethical Committee of the Faculty of Physical Culture, No. 17/2013. School-based anonymous surveys were conducted during April, May and June in 2002, 2006, 2010 and 2014 according to an international research protocol (35-38), resulting in a national representative sample of children who were in the fifth, seventh and ninth grades. The completion of the HBSC questionnaire was voluntary. The data cleaning was performed by the International Databank, University of Bergen, Norway, in compliance with the international HBSC standards (38). Age categories were governed by the HBSC protocol: the ' 11 ' age category included children aged 11.0-11.99 years, the ' 13 ' age category included children aged 13.0-13.99 years, and the ' 15 ', age category included children aged 15.0-15.99 years.

In 2002, the final data set for this analysis included 4,065 children (47.3\% of boys). In 2006, a total of 4,170 children (50.7\% of boys) were eligible for the analysis, and in 2010, 3,962 children ( $47.8 \%$ of boys) were eligible. Finally, the latest survey, in 2014 , included 4,338 children ( $48.9 \%$ of boys) for the screen time analysis.

\section{Assessment of Screen Time Behaviours}

In 2002, two items related to the time spent in front of a screen on weekdays and weekend days were used. The adolescents were asked the following questions: "About how many hours a day do you usually spend watching television (including DVDs and videos) in your free time?"; and "About how many hours a day do you usually spend using a computer (for playing games, emailing, chatting or surfing on the internet) in your free time?".

In 2006, 2010 and 2014, the question related to computer use was divided, and a total of three questions related to screen time on weekdays and weekend days were used: "About how many hours a day do you usually spend watching television (includ- ing DVDs and videos) in your free time?"; "About how many hours a day do you usually spend playing games on a computer or games console (PlayStation, Xbox, etc.) in your free time?"; and "About how many hours a day do you usually spend using a computer for chatting online, browsing the Internet, emailing, doing homework, etc. in your free time?".

For each question, the response options were 'none at all', 'about half an hour a day', 'about one hour a day', 'about two hours a day', 'about three hours a day', 'about four hours a day', 'about five hours a day', 'about six hours a day', and 'about seven or more hours a day'.

\section{Statistical Analysis}

Screen time was computed as the sum of time spent watching television, of computer use and of time spent gaming. To describe the overall differences in screen time by gender and age categories in more detail, we applied an analysis of variance approach with a dependent variable - sedentary time in hours - and the independent variables of gender (boys and girls) and age categories (11, 13 and 15 years old).

As a result of societal changes related to computer use after 2002, the analysis of time spent using a computer was carried out only between 2006 and 2014. For TV viewing, trends are shown between 2002 and 2014. Changes in the amount of time spent watching television and using a computer (including gaming) across the survey years were analysed by using the current recommendations of two hours per day or less (19-22, 39).

To determine the trend, a logistic regression analysis (Enter method) was used with a dependent variable - meeting the guideline for watching television and computer use of two hours per day or less - and an independent categorical variable, which was the year that the survey was completed, with 2002 and 2006, respectively, being used as reference years. For screen time, the same statistical procedure was followed.

\section{RESULTS}

The total screen time (i.e. summing together watching television, computer use and gaming) of the boys between 2002 and 2014 ranged from 4.3 to 6.9 hours per weekday and from 5.1 to 8.7 hours per weekend day. The total screen time of the girls ranged from 3.1 to 5.2 hours per weekday and from 3.7 to 6.6 hours per weekend day. Significant differences $(p<0.001)$ were found between the boys and girls and also between age categories (especially in comparison with the youngest age group) in screen time on weekend days, as well as weekdays, in all the survey years. The ' 11 ' age category shows significantly less screen time compared with the older adolescents. The girls reported significantly less screen time than the boys throughout all the survey waves (data not shown).

Table 1 displays the prevalence of Czech adolescents, by age category and gender, who engaged in two hours or less per day of watching television, as well as the odds ratio of meeting this guideline ( $\leq$ two hours per day) for the different survey years, with 2002 as the reference year. From 2010 to 2014, as compared with 2002, boys and girls were between 1.3 and 2.0 times more likely to meet the recommended time spent watching television. This 
Table 1. Trends in meeting current recommendations for watching television $\leq$ two hours per day, by age category and gender

\begin{tabular}{|c|c|c|c|c|c|c|c|c|c|c|c|c|c|}
\hline \multirow{3}{*}{ Variable } & \multirow{3}{*}{$\begin{array}{c}2002 \\
\%\end{array}$} & \multirow{3}{*}{$\begin{array}{c}2006 \\
\%\end{array}$} & \multirow{3}{*}{$\begin{array}{c}2010 \\
\%\end{array}$} & \multirow{3}{*}{$\begin{array}{c}2014 \\
\%\end{array}$} & \multicolumn{3}{|c|}{2006 vs. 2002} & \multicolumn{3}{|c|}{2010 vs. 2002} & \multicolumn{3}{|c|}{2014 vs. 2002} \\
\hline & & & & & \multirow{2}{*}{ OR } & \multicolumn{2}{|c|}{$\mathrm{Cl}$} & \multirow{2}{*}{ OR } & \multicolumn{2}{|c|}{$\mathrm{Cl}$} & \multirow{2}{*}{ OR } & \multicolumn{2}{|c|}{$\mathrm{Cl}$} \\
\hline & & & & & & Lower & Upper & & Lower & Upper & & Lower & Upper \\
\hline \multicolumn{14}{|c|}{ Weekdays } \\
\hline \multicolumn{14}{|l|}{ Boys } \\
\hline 11 years & 57.2 & 59.4 & 65.2 & 63.6 & 1.09 & 0.88 & 1.36 & $1.40^{* *}$ & 1.12 & 1.75 & $1.31^{*}$ & 1.05 & 1.63 \\
\hline 13 years & 49.2 & 56.3 & 60.5 & 64.2 & $1.33^{*}$ & 1.07 & 1.65 & $1.58^{* * *}$ & 1.26 & 1.99 & $1.85^{\star \star *}$ & 1.49 & 2.31 \\
\hline 15 years & 46.7 & 58.3 & 63.5 & 61.7 & $1.60^{* * *}$ & 1.29 & 1.98 & $1.99^{* * *}$ & 1.59 & 2.48 & $1.84^{\star * *}$ & 1.49 & 2.27 \\
\hline \multicolumn{14}{|l|}{ Girls } \\
\hline 11 years & 59.7 & 66.6 & 70.2 & 74.6 & $1.35^{* *}$ & 1.08 & 1.68 & $1.59^{* * *}$ & 1.27 & 1.99 & $1.99^{* * *}$ & 1.59 & 2.50 \\
\hline 13 years & 52.0 & 57.1 & 63.1 & 65.1 & 1.23 & 1.00 & 1.52 & $1.58^{* * *}$ & 1.28 & 1.95 & $1.72^{\star * *}$ & 1.40 & 2.12 \\
\hline 15 years & 55.6 & 64.0 & 68.5 & 65.1 & $1.42^{* *}$ & 1.15 & 1.76 & $1.73^{* * *}$ & 1.39 & 2.15 & $1.48^{* * *}$ & 1.20 & 1.83 \\
\hline \multicolumn{14}{|c|}{ Weekend days } \\
\hline \multicolumn{14}{|l|}{ Boys } \\
\hline 11 years & 45.4 & 44.0 & 50.7 & 46.2 & 0.95 & 0.76 & 1.17 & 1.24 & 1.00 & 1.54 & 1.04 & 0.83 & 1.29 \\
\hline 13 years & 38.3 & 37.7 & 41.7 & 43.7 & 0.98 & 0.78 & 1.22 & 1.15 & 0.92 & 1.45 & $1.25^{*}$ & 1.00 & 1.56 \\
\hline 15 years & 34.7 & 41.3 & 47.6 & 43.3 & $1.33^{*}$ & 1.06 & 1.65 & $1.71^{* * *}$ & 1.37 & 2.14 & $1.44^{\star * *}$ & 1.16 & 1.79 \\
\hline \multicolumn{14}{|l|}{ Girls } \\
\hline 11 years & 51.2 & 51.0 & 59.0 & 61.2 & 0.99 & 0.80 & 1.23 & $1.37^{* *}$ & 1.11 & 1.70 & $1.50^{* * *}$ & 1.22 & 1.86 \\
\hline 13 years & 41.1 & 42.6 & 44.5 & 49.5 & 1.06 & 0.86 & 1.32 & 1.15 & 0.93 & 1.42 & $1.40^{* *}$ & 1.14 & 1.72 \\
\hline 15 years & 48.6 & 45.7 & 51.8 & 44.8 & 0.89 & 0.72 & 1.10 & 1.14 & 0.92 & 1.40 & 0.86 & 0.70 & 1.05 \\
\hline
\end{tabular}

Results are based on logistic regression; \% percentage of participants who met the guideline for time spent watching TV $\leq$ two hours per day; OR: odds ratio (cohort from 2002 is a reference group); Cl: $95 \%$ confidence interval; ${ }^{*} p \leq 0.05,{ }^{* *} p \leq 0.01,{ }^{* * *} p \leq 0.001$

Table 2. Trends in meeting current recommendations for computer use and gaming $\leq$ two hours per day, by age category and gender

\begin{tabular}{|c|c|c|c|c|c|c|c|c|c|}
\hline \multirow{3}{*}{ Variable } & \multirow{3}{*}{$\begin{array}{c}2006 \\
\%\end{array}$} & \multirow{3}{*}{$\begin{array}{c}2010 \\
\%\end{array}$} & \multirow{3}{*}{$\begin{array}{c}2014 \\
\%\end{array}$} & \multicolumn{3}{|c|}{2010 vs. 2006} & \multicolumn{3}{|c|}{2014 vs. 2006} \\
\hline & & & & \multirow{2}{*}{ OR } & \multicolumn{2}{|c|}{$\mathrm{Cl}$} & \multirow{2}{*}{ OR } & \multicolumn{2}{|c|}{$\mathrm{Cl}$} \\
\hline & & & & & Lower & Upper & & Lower & Upper \\
\hline \multicolumn{10}{|c|}{ Weekdays } \\
\hline \multicolumn{10}{|l|}{ Boys } \\
\hline 11 years & 55.6 & 48.1 & 39.1 & $0.74^{* * *}$ & 0.60 & 0.92 & $0.51^{* *}$ & 0.41 & 0.64 \\
\hline 13 years & 46.8 & 31.0 & 30.3 & $0.51^{\text {*** }}$ & 0.41 & 0.64 & $0.49^{*}$ & 0.40 & 0.61 \\
\hline 15 years & 42.4 & 23.8 & 21.9 & $0.42^{* * *}$ & 0.34 & 0.54 & $0.38^{* * *}$ & 0.30 & 0.48 \\
\hline \multicolumn{10}{|l|}{ Girls } \\
\hline 11 years & 77.4 & 63.0 & 66.2 & $0.50^{* * *}$ & 0.39 & 0.63 & $0.57^{* * *}$ & 0.45 & 0.73 \\
\hline 13 years & 67.8 & 43.4 & 46.4 & $0.36^{* * *}$ & 0.29 & 0.45 & $0.41^{* * *}$ & 0.33 & 0.51 \\
\hline 15 years & 68.7 & 42.3 & 36.8 & $0.33^{* * *}$ & 0.27 & 0.42 & $0.27^{\star * \star}$ & 0.21 & 0.33 \\
\hline \multicolumn{10}{|c|}{ Weekend days } \\
\hline \multicolumn{10}{|l|}{ Boys } \\
\hline 11 years & 48.1 & 42.8 & 31.4 & 0.81 & 0.65 & 1.00 & $0.49^{* * *}$ & 0.39 & 0.62 \\
\hline 13 years & 36.8 & 27.8 & 22.4 & $0.66^{* * *}$ & 0.52 & 0.84 & $0.50^{* * *}$ & 0.39 & 0.63 \\
\hline 15 years & 31.8 & 17.9 & 17.7 & $0.47^{* * *}$ & 0.36 & 0.60 & $0.46^{* * *}$ & 0.36 & 0.59 \\
\hline \multicolumn{10}{|l|}{ Girls } \\
\hline 11 years & 72.6 & 61.2 & 56.0 & $0.60^{* * *}$ & 0.47 & 0.75 & $0.48^{* * *}$ & 0.38 & 0.60 \\
\hline 13 years & 61.3 & 38.0 & 39.8 & $0.39^{* * *}$ & 0.31 & 0.48 & $0.42^{\star * \star}$ & 0.34 & 0.52 \\
\hline 15 years & 58.4 & 32.2 & 31.3 & $0.34^{* * *}$ & 0.27 & 0.42 & $0.32^{* * *}$ & 0.26 & 0.40 \\
\hline
\end{tabular}

Results are based on logistic regression; \% percentage of participants who met the guideline for time spent using computer $\leq$ two hours per weekend day; OR: odds ratio (cohort from 2002 is a reference group); Cl: $95 \%$ confidence interval; ${ }^{*} p \leq 0.05,{ }^{* *} p \leq 0.01,{ }^{* * *} p \leq 0.001$ 
positive trend (in the reduction of time spent watching television) on weekdays was observed regardless of gender and age category and was statistically significant.

A comparison with respect to weekend days between 2014 and 2002 revealed a similar positive trend that was significant with regard to time spent watching television (in terms of a reduction in the amount of time spent watching television), but it was not significant among the 11-year-old boys and 15-year-old girls. The changes in the amount of time spent watching television between 2006 and 2002 were not as pronounced as in the years that followed (Table 1).

In 2014 , only between $31 \%$ and $56 \%$ of the girls and between $17 \%$ and $31.4 \%$ of the boys used a computer (including gaming and other purposes) for two hours or less per weekend day (Table 2). The trends also indicate that adolescents in 2014 were significantly less likely to meet the current recommendations for using a computer for two hours per day or less, compared with those surveyed in 2006. This significant increase in computer overuse in 2014 was observed among all age categories and for both boys and girls. Similar results were found for weekdays. All the odds ratios were statistically significant and $<1$.

Considering the prevalence of those meeting the current recommendations for total screen time (the aggregate amount of time spent watching television and on computer use) in 2014, only $8.4 \%$ of the boys and $15.9 \%$ of the girls reported two hours or less per weekend day and $11.1 \%$ of the boys and $23 \%$ of the girls per weekday. Regardless of age category, a comparison between 2014 and 2006 revealed a significant decrease in the proportion of boys $(\mathrm{OR}=0.74,95 \% \mathrm{CI}=0.62-0.89)$ and girls $(\mathrm{OR}=0.80$, $95 \% \mathrm{CI}=0.70-0.92)$ spending two hours per day or less on their total screen time (data not shown).

The results also suggested that the 15 -year-old boys and girls were less likely to meet the guideline for total screen time of two hours or less per weekday $\left(\mathrm{OR}_{\text {boys }}=0.57,95 \% \mathrm{CI}=0.40-0.81\right.$; ORgirls $=0.47,95 \% \mathrm{CI}=0.36-0.61)$, as well as per weekend day $(\mathrm{OR}-$ $\left.{ }_{\text {boys }}^{\text {girls }}=0.66,95 \% \mathrm{CI}=0.44-0.97 ; \mathrm{OR}_{\text {girls }}=0.52,95 \% \mathrm{CI}=0.39-0.71\right)$ compared to the other age groups (data not shown).

\section{DISCUSSION}

Our study of trends in screen time behaviour between 2002 and 2014 indicated that TV viewing has decreased in Czech adolescents aged 11 to 15 . We observed a decrease in watching TV between 2002 and 2014. In 2014, roughly two-thirds of the adolescents watched television for less than two hours per weekend day. This positive development is reversed by a strong increase in computer use in both boys and girls. Summing all screen time up, only a minority of adolescents meet the current recommendations of two hours or less of recreational screen time. Our study presents important findings with regard to Central and Eastern European countries since the estimates of prevalence found were provided by a reliable and internationally established tool.

\section{Current Prevalence}

Our data on 11- to 15-year-old Czech schoolchildren in 2014 indicated that roughly two-thirds of the children watched television for less than two hours per weekend day. Similar results were observed in a study of US children and adolescents, where three quarters of the adolescents did not exceed two hours of screen watching per day (29). At weekends, less than half of the Czech schoolchildren (except 11-year-old girls) fulfilled these current recommendations.

In contrast, the proportion of Czech children who spent less time than two hours per day using a computer in 2014 varied between $17 \%$ (15-year-old boys) and 56\% (11-year-old girls). With regard to total screen time (television and computer), only $23 \%$ of the girls and less than $12 \%$ of the boys met the guideline. Similar findings were shown for German and Canadian youngsters (25, 40). Markedly more positive results in terms of current screen time recommendations were also found in 13- to 18-year-old Chinese children and also in 9- to 10-year-old Texan children, where most children did not exceed two hours per day watching television and using a computer $(41,42)$. Similarly to other studies $(40,43)$, our study confirmed that boys and older adolescents are less likely to meet the current screen time recommendations.

\section{Trends in Screen Time Behaviours}

A favourable result of our study was an increase in the prevalence of Czech schoolchildren not exceeding two hours per day spent watching television. A stagnation or decline in time spent watching television was also observed among German adolescents (25), Australian children (43), US adolescents $(24,31)$ and Brazilian adolescents (44); similar trends were observed in 29 (mostly European) countries involved in the HBSC study (45).

In contrast to the decline in watching television, our study revealed a significant increase in the prevalence of children who exceeded two hours per day of using a computer (chatting, playing games, browsing the Internet etc.); a similar increasing trend in computer use was identified in other countries, such as Germany, Brazil, the US, and Australia $(25,27,31,43)$. Although a study of US children aged 9-13 suggests that a decrease in time spent watching television is replaced by time spent using a computer (29), in other longitudinal or secular trend studies $(27,31,46$, 47 ), and also in the present study, time spent using a computer is increasing faster compared with the decline in that spent watching television. In sum, we note an increase in total screen time among Czech schoolchildren between 2006 and 2014.

\section{Public Health Implications}

Cross-sectional studies of watching television and computer use in children and adolescents indicate that children who spend more time watching television are more likely to be overweight or obese and also to be less physically active $(19,30,48,49)$. In general, screen time is important contribution to the overall time spent indulging in sedentary behaviour. Several systematic reviews highlight the detrimental effects of being sedentary in terms of physical, mental and social health outcomes (12-17). In addition, a higher amount of screen time is associated with unhealthy eating habits or higher consumption of tobacco or alcohol $(16,50)$.

Knowledge of secular trends in children's sedentary behaviour is necessary to inform researchers, the public and policymakers in order to highlight the need for effective interventions. Furthermore, trends are a suitable way to monitor the success of popula- 
tion-wide approaches to changing health-related behaviours such as screen time. Our data showed an increase in the total screen time of school-aged children in the Czech Republic between 2002 and 2014, which underlines the need for the development of effective intervention programmes focused on reducing sedentary time.

The current findings are valuable for Central and Eastern Europe from a methodological point of view as well. First, there was a lack of recent data estimating prevalence and changes in time spent on screen-based behaviour or sedentary behaviours across Central and Eastern Europe. In addition to that, these results are limited and vary between countries (23-27). Some studies reported a consistent amount of total time spent sitting in front of the television or computer, and they reveal that television watching time was replaced by time spent using a computer $(28$, 29). Other studies found an increase in the time spent sitting in front of a television or a computer (30-32). The need for further analyses using the same methodology in different countries is needed to allow sound comparisons between countries. We approached this issue by using an established and internationally recognised tool from the HSBC study. Although the HBSC items related to screen time behaviour showed moderate to borderline reliability $(33,34)$, the results are satisfactory as approximately $60-80 \%$ of the respondents selected the identical or an adjacent response category both in the test and retest stage of the study. Moreover, the reliability using a shortened test-and-retest period was greater (34).

Our study has several limitations, though. First, we used selfreported measures of screen time; on the other hand, previous studies have reported reasonable reliability and validity regarding this measure $(34,51)$. Second, we were not able to compare computer use with the 2002 data (as this was done in a television watching analysis), as a result of societal changes in items related to computer use; therefore, we compared computer use and gaming time with the reference year 2006. In addition, screen time is only one part of adolescents' sedentary time, but time spent in a sedentary manner watching television or using a computer is commonly used as an indicator of sedentary behaviour among youngsters (9).

Finally, we observed a significant decrease in television watching time but also a significant increase in computer use and gaming. Overall, the decrease in time spent watching television is replaced by time spent using a computer, and we noticed a significant increase in total screen time, especially in the 15-year-old adolescents. As expected, older adolescents and boys in particular reported more screen time as a result of the activities noted above. This negative trend in total screen time suggests that more focused public health interventions are needed to reduce the number of hours of leisure time spent on sedentary activities - watching television or using a computer. Our findings could be used as a reference for the development of policymaking and intervention programmes aiming to increase physical activity and reduce sedentary behaviour (36) in this region.

\section{Acknowledgements}

We would like to thank the colleagues who conducted the HBSC study in the respective survey years. In 2002, the HBSC study in the Czech Republic was coordinated by the Prague Psychiatric Centre. In 2006 the study moved to the National Institute of Public Health in Prague, and in 2010 the coordinating role in the study was transferred to the Faculty of Physical Culture of Palacký University, Olomouc, where it remains till the present.

This work was supported by the research grant of the Czech Science Foundation Reg. No. 17-12579S and by the Czech Ministry of Education, Youth and Sports (MEYS) under Contract No. LG 14043.

\section{Conflict of Interests}

None declared

\section{REFERENCES}

1. Biddle SJ, Gorely T, Marshall SJ, Cameron N. The prevalence of sedentary behavior and physical activity in leisure time: a study of Scottish adolescents using ecological momentary assessment. Prev Med. 2009;48(2):151-5.

2. Malina RM. Youth, sport and physical activity. In: Coelho-E-Silva M, Cupido-dos-Santos A, Figueiredo AJ, Armstrong N, Ferreira JP, editors. Children and exercise XXVIII : the proceedings of the 28th Pediatric Work Physiology Meeting. London: Routledge; 2014. p. 5-30.

3. Hamrik Z, Kalman M, Sigmundová D, Pavelka J, Salonna F. Screenbased behaviour in Czech adolescents is more prevalent at weekends. Acta Gymnica. 2014;44(4):203-9.

4. Stankiewicz M, Pieszko M, Šliwińska A, Małgorzewicz S, Wierucki Ł, Zdrojewski T, et al. Obesity and diet awareness among Polish children and adolescents in small towns and villages. Cent Eur J Public Health. 2014;22(1):12-6.

5. Pearson N, Braithwaite RE, Biddle SJ, van Sluijs EM, Atkin AJ. Associations between sedentary behaviour and physical activity in children and adolescents: a meta-analysis. Obes Rev. 2014;15(8):666-75.

6. Schmid D, Ricci C, Leitzmann MF. Associations of objectively assessed physical activity and sedentary time with all-cause mortality in US adults: the NHANES study. PloS One. 2015;10(3):e0119591. doi: 10.1371/ journal.pone.0119591.

7. Biddle SJ, Pearson N, Ross GM, Braithwaite R. Tracking of sedentary behaviours of young people: a systematic review. Prev Med. 2010;51(5):345-51.

8. Busschaert C, Cardon G, Van Cauwenberg J, Maes L, Van Damme J, Hublet A, et al. Tracking and predictors of screen time from early adolescence to early adulthood: a 10-year follow-up study. J Adolesc Health. 2015;56(4):440-8.

9. Machado-Rodrigues AM, Leite N, Coelho-e-Silva MJ, Enes F, Fernandes $\mathrm{R}$, Mascarenhas LP, et al. Metabolic risk and television time in adolescent females. Int J Public Health. 2015;60(2):157-65.

10. Brindova D, Dankulincova Veselska Z, Klein D, Hamrik Z, Sigmundova $\mathrm{D}$, van Dijk JP, et al. Is the association between screen-based behaviour and health complaints among adolescents moderated by physical activity? Int J Public Health. 2015;60(2):139-45.

11. Nuutinen T, Roos E, Ray C, Villberg J, Välimaa R, Rasmussen M, et al. Computer use, sleep duration and health symptoms: a crosssectional study of 15-year olds in three countries. Int J Public Health. 2014;59(4):619-28.

12. Bickham DS, Hswen Y, Rich M. Media use and depression: exposure, household rules, and symptoms among young adolescents in the USA. Int J Public Health. 2015;60(2):147-55

13. Tremblay MS, LeBlanc AG, Kho ME, Saunders TJ, Larouche R, Colley $\mathrm{RC}$, et al. Systematic review of sedentary behaviour and health indicators in school-aged children and youth. Int J Behav Nutr Phys Act. 2011;8:98. doi: 10.1186/1479-5868-8-98.

14. Rasmussen M, Meilstrup CR, Bendtsen P, Pedersen TP, Nielsen L, Madsen $\mathrm{KR}$, et al. Perceived problems with computer gaming and internet use are associated with poorer social relations in adolescence. Int J Public Health. 2015;60(2):179-88.

15. Epstein JA. Adolescent computer use and alcohol use: what are the role of quantity and content of computer use? Addict Behav. 2011;36(5):520-2.

16. Gommans R, Stevens GW, Finne E, Cillessen AH, Boniel-Nissim M, ter Bogt TF. Frequent electronic media communication with friends is associated with higher adolescent substance use. Int J Public Health. 2015;60(2):167-77.

17. Valkenburg PM, Peter J. Online communication among adolescents an integrated model of its attraction, opportunities, and risks. J Adolesc Health. 2011;48(2):121-7. 
18. Boniel-Nissim M, Lenzi M, Zsiros E, de Matos MG, Gommans R, HarelFisch Y, et al. International trends in electronic media communication among 11- to 15-year-olds in 30 countries from 2002 to 2010: association with ease of communication with friends of the opposite sex. Eur J Public Health. 2015;25 Suppl 2:41-5.

19. Salmon J, Campbell KJ, Crawford DA. Television viewing habits associated with obesity risk factors: a survey of Melbourne schoolchildren. Med J Aust. 2006;184(2):64-7.

20. Kaur H, Choi WS, Mayo MS, Harris KJ. Duration of television watching is associated with increased body mass index. J Pediatr. 2003;143(4):50611.

21. American Academy of Pediatrics, Committee on Public Education Children, adolescents, and television. Pediatrics. 2001;107(2):423-6.

22. Tremblay MS, LeBlanc AG, Janssen I, Kho ME, Hicks A, Murumets K, et al. Canadian sedentary behaviour guidelines for children and youth. Appl Physiol Nutr Metab. 2011;36(1):59-64.

23. Coll Cde V, Knuth AG, Bastos JP, Hallal PC, Bertoldi AD. Time trends of physical activity among Brazilian adolescents over a 7-year period. J Adolesc Health. 2014;54(2):209-13.

24. Iannotti RJ, Wang J. Trends in physical activity, sedentary behavior, diet, and BMI among US adolescents, 2001-2009. Pediatrics. 2013;132(4):60614.

25. Bucksch J, Inchley J, Hamrik Z, Finne E, Kolip P; HBSC Study Group Germany. Trends in television time, non-gaming PC use and moderateto-vigorous physical activity among German adolescents 2002-2010. BMC Public Health. 2014;14:351. doi: 10.1186/1471-2458-14-351.

26. Hallal PC, Andersen LB, Bull FC, Guthold R, Haskell W, Ekelund U. Global physical activity levels: surveillance progress, pitfalls, and prospects. Lancet. 2012;380(9838):247-57.

27. Silva KS, da Silva Lopes A, Dumith SC, Garcia LM, Bezerra J, Nahas MV. Changes in television viewing and computers/videogames use among high school students in Southern Brazil between 2001 and 2011. Int J Public Health. 2014;59(1):77-86.

28. Sigmundová D, El Ansari W, Sigmund E, Frömel K. Secular trends: a ten-year comparison of the amount and type of physical activity and inactivity of random samples of adolescents in the Czech Republic. BMC Public Health. 2011;11:731. doi: 10.1186/1471-2458-11-731.

29. Huhman M, Lowry R, Lee SM, Fulton JE, Carlson SA, Patnode CD. Physical activity and screen time: trends in U.S. children aged 9-13 years, 2002-2006. J Phys Act Health. 2012;9(4):508-15.

30. Dumith SC, Garcia LM, da Silva KS, Menezes AM, Hallal PC. Predictors and health consequences of screen-time change during adolescence1993Pelotas (Brazil) birth cohort study. J Adolesc Health. 2012;51(6 Suppl):S16-21.

31. Nelson MC, Neumark-Stzainer D, Hannan PJ, Sirard JR, Story M. Longitudinal and secular trends in physical activity and sedentary behavior during adolescence. Pediatrics. 2006;118(6):e1627-34.

32. Gebremariam MK, Totland TH, Andersen LF, Bergh IH, Bjelland M, Grydeland M, et al. Stability and change in screen-based sedentary behaviours and associated factors among Norwegian children in the transition between childhood and adolescence. BMC Public Health. 2012;12:104. doi: 10.1186/1471-2458-12-104.

33. Liu Y, Wang M, Tynjälä J, Lv Y, Villberg J, Zhang Z, et al. Test-retest reliability of selected items of Health Behaviour in School-aged Children (HBSC) survey questionnaire in Beijing, China. BMC Med Res Methodol. 2010;10:73. doi: 10.1186/1471-2288-10-73.

34. Bobakova D, Hamrik Z, Badura P, Sigmundova D, Nalecz H, Kalman M. Test-retest reliability of selected physical activity and sedentary behaviour HBSC items in the Czech Republic, Slovakia and Poland. Int J Public Health. 2015;60(1):59-67.

35. Currie C, Samdal O, Boyce W, Smith R, editors. Health behaviour in school-aged children: a WHO cross-national study (HBSC), research protocol for the 2001/2002 survey. Edinburgh: CAHRU; 2001.
36. Currie C, Gabhainn SN, Godeau E, Roberts C, Smith R, Currie D, et al., editors. Inequalities in young people's health: HBSC international report from the 2005/2006 survey. Copenhagen: WHO Regional Office for Europe; 2008.

37. Currie C, Griebler R, Inchley J, Theunissen A, Molcho M, Samdal O, Dur W, et al., editors. Health Behaviour in School-Aged Children (HBSC) study protocol: background, methodology and mandatory items for the 2009/10 survey. Edinburgh: CAHRU; 2011.

38. Currie C, Inchley J, Molcho M, Lenzi M, Veselska Z, Wild F, editors. Health Behaviour in School-aged Children (HBSC) study protocol: background, methodology and mandatory items for the 2013/14 survey. St Andrews: Child and Adolescent Health Research Unit (CAHRU); 2014.

39. Canadian Paediatric Society. Impact of media use on children and youth. Paediatr Child Health. 2003;8(5):301-6.

40. Mark AE, Boyce WF, Janssen I. Television viewing, computer use and total screen time in Canadian youth. Paediatr Child Health. 2006;11(9):5959.

41. Cui Z, Hardy LL, Dibley MJ, Bauman A. Temporal trends and recent correlates in sedentary behaviours in Chinese children. Int J Behav Nutr Phys Act. 2011;8(1):93. doi: 10.1186/1479-5868-8-93.

42. Ezendam NP, Springer AE, Brug J, Oenema A, Hoelscher DH. Do trends in physical activity, sedentary, and dietary behaviors support trends in obesity prevalence in 2 border regions in Texas? J Nutr Educ Behav. 2011;43(4):210-8

43. Hesketh K, Wake M, Graham M, Waters E. Stability of television viewing and electronic game/computer use in a prospective cohort study of Australian children: relationship with body mass index. Int J Behav Nutr Phys Act. 2007;4:60. doi: 10.1186/1479-5868-4-60.

44. Lopes AS, Silva KS, Barbosa Filho VC, Bezerra J, de Oliveira ES, Nahas MV. Trends in screen time on week and weekend days in a representative sample of Southern Brazil students. J Public Health. 2014;36(4):608-14.

45. Bucksch J, Sigmundova D, Hamrik Z, Troped PJ, Melkevik O, Ahluwalia $\mathrm{N}$, et al. International trends in adolescent screen-time behaviors from 2002 to 2010. J Adolesc Health. 2016 Apr;58(4):417-25.

46. Brodersen NH, Steptoe A, Boniface DR, Wardle J. Trends in physical activity and sedentary behaviour in adolescence: ethnic and socioeconomic differences. Br J Sports Med. 2007;41(3):140-4.

47. Duncan M, Vandelanotte C, Caperchione C, Hanley C, Mummery WK. Temporal trends in and relationships between screen time, physical activity, overweight and obesity. BMC Public Health. 2012;12:1060. doi: 10.1186/1471-2458-12-1060.

48. Marshall SJ, Biddle SJ, Gorely T, Cameron N, Murdey I. Relationships between media use, body fatness and physical activity in children and youth: a meta-analysis. Int J Obes Relat Metab Disord. 2004;28(10):123846

49. Olafsdottir S, Eiben G, Prell H, Hense S, Lissner L, Mårild S, et al. Young children's screen habits are associated with consumption of sweetened beverages independently of parental norms. Int J Public Health. 2014;59(1):67-75

50. Francis LA, Lee Y, Birch LL. Parental weight status and girls' television viewing, snacking, and body mass indexes. Obes Res. 2003;11(1):143-51.

51. Rey-López JP, Vicente-Rodriguez G, Ortega FB, Ruiz JR, Martinez-Gómez D, De Henauw S, et al. Sedentary patterns and media availability in European adolescents: The HELENA study. Prev Med. 2010;51(1):50-5. 